\title{
VALIDATION OF AN ASCOSPORE RELEASE PREDICTION MODEL FOR APPLE BLACK SPOT (VENTURIA INAEQUALIS)
}

\author{
R.M. BERESFORD
}

\begin{abstract}
The Horticulture and Food Research Institute of New Zealand Ltd, Private Bag 92-169, Auckland
\end{abstract}

\begin{abstract}
A computer model, which uses degree days to simulate ascospore maturation and daily rainfall to simulate release of mature ascospores, was tested on observed ascospore release data. The mean number of degree days from 22 August to 50\% ascospore maturation for the observed data $\left(653{ }^{\circ} \mathrm{C}\right.$ days) was not significantly different from the model value of $534^{\circ} \mathrm{C}$ days. The mean difference between modelled and observed percentage release for 79 individual sampling periods was not significantly different from zero, indicating that the model was not biased towards over- or under-prediction. Ninety percent of the modelled predictions were within $\pm 10 \%$ of the observed ascospore counts, indicating good precision. The model accurately identified occasions when $<5 \%$ ascospore release occurred and when substantial release followed dry weather.
\end{abstract}

Keywords: Apple scab, ascospore discharge, degree days, rainfall, disease prediction model.

\section{INTRODUCTION}

Ascospores are the main source of primary inoculum for black spot (Venturia inaequalis) infection in apple orchards and are released over a 1-2 month season in spring, starting around bud burst. Ascospore numbers vary enormously from day to day during the release season, according to the stage of ascospore maturation and the occurrence of daytime rainfall (Brook 1976). Apple growers currently control ascospore infection by applying protective fungicide sprays every 7-10 days and curative sprays after infection periods have been monitored with an infection warning system (Beresford and Spink 1992; Laurenson et al. 1994; Laurenson and Beresford 1996). New Zealand apple growers, however, currently have no way of knowing when the greatest risk of ascospore release occurs.

Degree day models which describe ascospore maturation have been developed overseas (e.g. Gadoury and MacHardy 1982; Schwabe et al. 1989), giving growers knowledge of when the release season begins, when it is likely to peak and when it ends. These models do not, however, identify the numbers of ascospores released from day to day. An ascospore release prediction model, which uses a degree day model in conjunction with rainfall to predict daily ascospore release, has been developed from New Zealand historical ascospore release data (Beresford 1998). The testing of this model using ascospore release observations collected in five New Zealand apple growing regions during the 1998-99 growing season is described.

\section{Ascospore release model description}

\section{MATERIALS AND METHODS}

Ascospore maturation is modelled by a non-linear logistic function which predicts the cumulative percentage of the season's ascospores matured at any number of degree days, above a base temperature of $0{ }^{\circ} \mathrm{C}$, summed from 22 August:

Cumulative $\%$ ascospore maturation $=100 / 1+\mathrm{e}^{-0.01 \times(\text { degree days }-534)}$

Fifty percent maturation occurs when $534^{\circ} \mathrm{C}$ days have accumulated, and the rate parameter of 0.01 describes how fast maturation proceeds. Both these parameters are 
fixed for all regions. The percentage of ascospores available for release on any given day is the difference in percentage maturation between the given day and the previous day. Ascospores are released on days when there is $0.2 \mathrm{~mm}$ of rainfall between 0600 and 2000 hours. If the rainfall criterion is not fulfilled, unreleased ascospores are accumulated and then released, along with newly matured spores, on the next day with $0.2 \mathrm{~mm}$ of rainfall.

\section{Ascospore release data for model validation}

Ascospore release was monitored in five regions (one site in each of Auckland, Gisborne, Hawke's Bay, Nelson and Otago) from 19 August to 14 December 1998 using the exposed glass slide monitoring method (Manktelow and Beresford 1995). At each site, five replicate slides were exposed for 3-7 day periods over black spot-diseased leaves of apple cv. Gala, which were collected from one orchard block in Hawke's Bay in June 1998, then overwintered at each monitoring site. After each exposure period, slides were examined at 300X magnification and ascospores within 1-3 transects were counted. Each slide count was square root transformed, replicate means of transformed counts were taken, and the squares of these means were used for calculating cumulative percentages. The mean count for each exposure period at each site was expressed as a percentage of the final cumulative total mean count for each site.

\section{Weather data for model validation}

The model used temperature and rainfall data from electronic weather stations (Beresford and Spink 1992) at each of the ascospore monitoring sites. Daily mean temperatures for degree day accumulations were calculated from hourly air temperature readings in a thermometer screen $1.4 \mathrm{~m}$ above ground level. Rainfall was recorded hourly using a tipping bucket rain gauge with $0.1 \mathrm{~mm}$ sensitivity, also mounted $1.4 \mathrm{~m}$ above ground. The model produced daily output of percentage ascospore release and these percentages were accumulated over the number of days at each monitoring site corresponding to the glass slide exposure periods.

\section{RESULTS}

The duration of the modelled ascospore release season generally agreed with the observed release season (Fig. 1), although there was variability among the regions, with Gisborne and Otago being somewhat later.

To quantify the time that $50 \%$ maturation occurred from the observed ascospore release data at the five sites, the cumulative curves in Fig. 1 were linearized by logit transformation. Then, linear regression equations were fitted, using degree days. The regression parameters for each region were used to calculate the number of degree days at which $50 \%$ release occurred for the observed data (Table 1). The overall mean value across all regions of $653{ }^{\circ} \mathrm{C}$ days was greater than the value of $534^{\circ} \mathrm{C}$ days used in the model, however, the model's value was contained within the $95 \%$ confidence band of the observed data (Table 1). There was no systematic variation in the number of degree days to $50 \%$ maturation with latitude, suggesting that the degree day model was appropriate for all regions.

TABLE 1: Regression parameters of lines fitted to logit ascospore release, and degree days to $50 \%$ release for observed data in five regions.

\begin{tabular}{lccc}
\hline Region & Slope & $\begin{array}{c}\text { Intercept at start of } \\
{ }^{\circ} \mathrm{C} \text { day accumulations }\end{array}$ & $\begin{array}{c}{ }^{\circ} \mathrm{C} \text { days for } \\
50 \% \text { release }\end{array}$ \\
\hline Auckland & 0.0089 & -5.06 & 567 \\
Gisborne & 0.0091 & -6.96 & 768 \\
Hawke's Bay & 0.0125 & -6.62 & 529 \\
Nelson & 0.0096 & -6.18 & 642 \\
Otago & 0.0109 & -8.25 & 757 \\
\cline { 2 - 4 } & & 95\% confidence interval & 134 \\
\cline { 2 - 4 } & \multicolumn{5}{r}{$50 \%$ release value from the model } & 534 \\
\hline
\end{tabular}



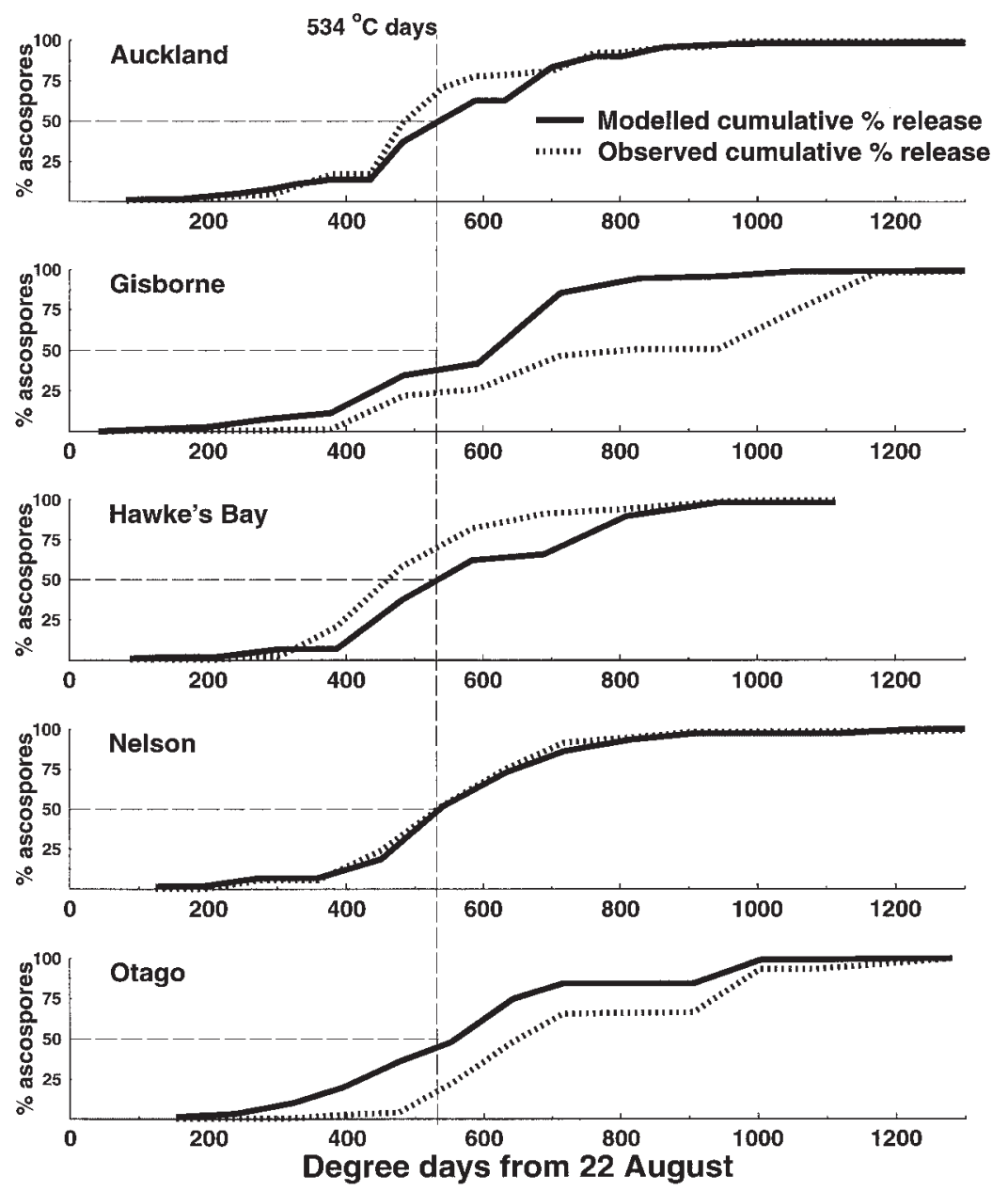

FIGURE 1: Cumulative percentage ascospore release predicted by the ascospore release model and that observed from glass slide ascospore counts in five regions during spring 1998.

The accuracy of the model was examined by calculating differences between the modelled and observed percentage ascospore release for the 79 individual exposure periods from all sites combined (Fig. 2). Differences were smallest when the release rate was smallest, at the beginning and end of the season. The mean value of the differences was only $0.18 \%$ (s.e. $=0.86$ ), which was not significantly different from zero, indicating that the model had no overall bias towards over- or under-prediction. Although there were differences of up to $25 \%$ between modelled and observed ascospore release for some exposure periods, $90 \%$ of the modelled predictions were within $\pm 10 \%$ of the observed ascospore counts, indicating that precision of the model predictions was good. 


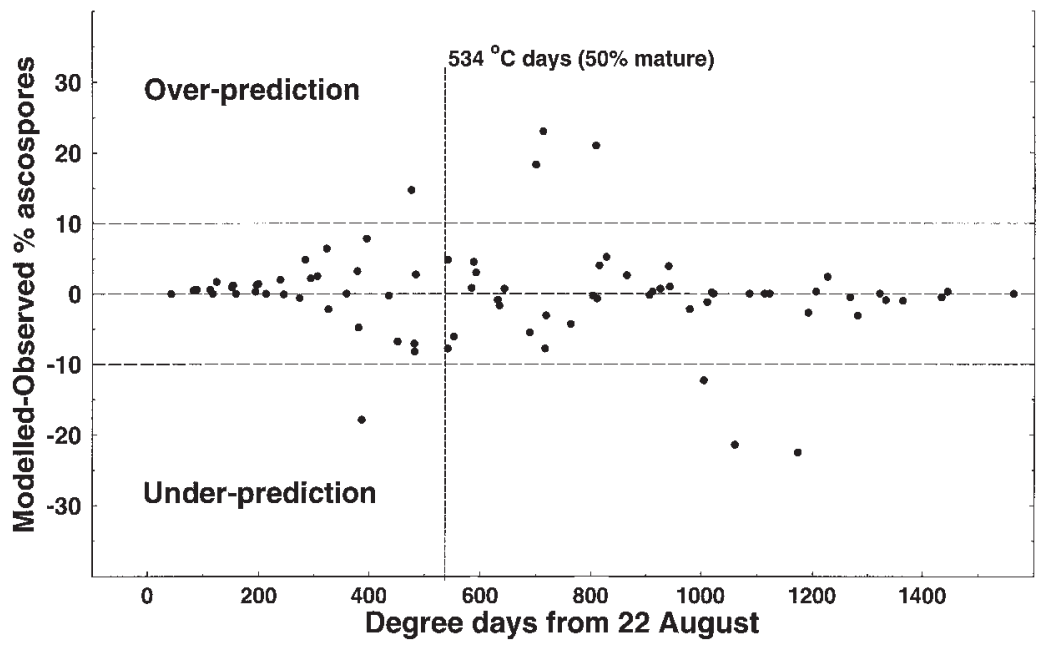

\section{FIGURE 2: Differences between modelled and observed percentage ascospore release for 79 exposure periods in five regions during spring 1998.}

On all the occasions when the model predicted zero ascospore release, observed ascospore release was $<5 \%$, showing that the model could accurately identify when negligible ascospore release occurred. The model correctly predicted 10 exposure periods that had substantial ascospore release which came after dry exposure periods with insufficient rainfall to release spores. On one occasion, in Hawke's Bay, some ascospore release was observed in an exposure period when there was $<0.2 \mathrm{~mm}$ of daytime rainfall. The only rainfall in that exposure period was $0.6 \mathrm{~mm}$ near midnight on one night and the observed ascospore release could not be explained.

\section{DISCUSSION}

This ascospore prediction model represents a significant advance over previously developed degree day models for ascospore maturation, since it predicts the risk of ascospore release from day to day, rather than just the underlying potential for release according to the stage in the ascospore release season. Use of this model has shown that rainfall, which triggers ascospore release, rather than temperature, which drives ascospore maturation, is the major determinant of airborne ascospore numbers. This is particularly true in climates where spring rainfall occurs sporadically, such as New Zealand's east coast horticultural regions.

The present model predicts percentages of the season's total ascospores that are released daily. Actual numbers of ascospores will depend on the amount of inoculum that has been overwintered in individual orchard blocks. The model's output will therefore be more useful when used in conjunction with assessments of potential ascospore dose (Gadoury and MacHardy 1986) to estimate absolute numbers of ascospores released.

The accuracy of the model appears adequate for use in improving the management of fungicides for black spot control. Four ways in which the model could help New Zealand apple growers make decisions on fungicide use are: 1) Identifying the start of the ascospore release season in relation to green tip so that the need for early fungicide protection can be assessed; 2) Identifying exactly when the rapid increase in ascospore maturation between green tip and full bloom occurs, so that fungicide protection can be maintained over the period of highest infection risk; 3) Identifying when a lack of 
daytime rainfall results in little risk of ascospore release and identifying when rainfall after a dry period causes a major ascospore release event; 4) Identifying the end of the ascospore release season so that growers who have achieved good control of ascospore infection can safely reduce the intensity of fungicide applications.

Computer software, which will allow this model to be used in the apple industry, is being developed. The model can be run using data from existing weather station networks (Beresford and Spink 1992). Its use in conjunction with infection period monitoring and potential ascospore dose assessment will allow greater optimization in timing fungicide applications against apple black spot in New Zealand apple orchards.

\section{ACKNOWLEDGEMENTS}

The ascospore counts used for model validation in this study were made by $\mathrm{Dr}$ Shaun Pennycook, and the glass slides for ascospore monitoring in regions were collected by Gavin Loudon, Peter Wood, Mike Kearney and Ross Marshall.

\section{REFERENCES}

Beresford, R.M., 1998. A model to predict daily release of Venturia inaequalis ascospores in New Zealand apple orchards. Proc. 7th Internat. Congress of Plant Path.: Abstr. no. 2.1.11.

Beresford, R.M. and Spink, M., 1992. A national disease forecasting system for apple black spot (Venturia inaequalis) in New Zealand. Acta Horticulturae 313: 285-296.

Brook, P.J., 1976. Seasonal pattern of maturation of Venturia inaequalis ascospores in New Zealand. N.Z. J. Agric. Res. 19: 103-109.

Gadoury, D.M. and MacHardy, W.E., 1982. A model to estimate the maturity of ascospores of Venturia inaequalis. Phytopath. 72: 901-904.

Gadoury, D.M. and MacHardy, W.E., 1986. Forecasting ascospore dose of Venturia inaequalis in commercial apple orchards. Phytopath. 76: 112-118.

Laurenson, M.R. and Beresford, R.M., 1996. Decision support software as a medium for technology transfer in plant protection. Proc. 49th N.Z. Plant Prot. Conf.: 85-89.

Laurenson, M.R., Buwalda, J.G. and Walker, J.T.S., 1994. Orchard 2000 - a decision support system for New Zealand's orchard industries. N.Z. J. Crop and Hort. Sci. 22: $239-250$.

Manktelow, D.W.L. and Beresford, R.M., 1995. Evaluation of an ascospore monitoring method for Venturia inaequalis to improve apple black spot fungicide management. Proc. 48th N.Z. Plant Prot. Conf.: 78-82.

Schwabe, W.F.S., Jones, A.L. and van Blerk, E., 1989. Relation of degree-day accumulations to maturation of ascospores of Venturia inaequalis in South Africa. Phytophylactica 21: 13-16. 